\title{
ANALYSIS OF MULTIPLE BIRTH RATES IN JAPAN V. SEASONAL AND SOCIAL CLASS VARIATIONS IN TWIN BIRTHS
}

\author{
Yoko Imalzumi, ${ }^{1}$ Akio AsAKa, ${ }^{2}$ and Eiji INOUYE ${ }^{2}$ \\ ${ }^{1}$ Institute of Population Problems, Ministry of Health and Welfare, \\ Tokyo 100, Japan \\ ${ }^{2}$ Institute of Brain Research, University of Tokyo School of \\ Medicine, Tokyo 113, Japan
}

\begin{abstract}
Summary Seasonal variation in twin births was studied in Japan using data on 12,392 pairs of twins in 1974. The highest twinning rates per 1,000 births for MZ (4.56) and DZ (2.20) twins were seen in April, the lowest rate in September (3.69) for $\mathrm{MZ}$ twins and in July (1.71) for DZ twins.

Occupation of the heads of the household did not affect twinning rate in Japan. On the other hand, social class variation was indicated in stillbirth rates of twins for both $\mathrm{MZ}$ and $\mathrm{DZ}$ twins. The highest stillbirth rate of $M Z$ twins was seen in "Others" $(0.2157)$ and the lowest one in "Agriculture with other works" (0.1179). In DZ twins the highest stillbirth rate was similarly seen in "Others" $(0.1529)$, but the lowest one in "Employee-white collar" $(0.0842)$.
\end{abstract}

\section{INTRODUCTION}

Dizygotic twinning rates are known to vary according to racial and geographical factors as well as maternal age and birth order. Besides, Lilienfeld and Pasamanick (1955) reported that socioeconomic factor influenced the twinning rate. Present study deals with seasonal and social class variations in overall birth rates and stillbirth rates of twins.

\section{MATERIALS AND METHODS}

Source of data is the "Survey on Socio-Economic Aspects of Vital Events-Plural Births in 1975" (Health and Welfare Statistics and Information Department, Ministry of Health and Welfare, Japan). This survey consists of two surveys, A and B. In the present study only Survey A was used, which includes data on 12,392 twin 
pairs derived from certificate records on the live birth and fetal death (after the beginning of the fourth month of fetal life) for all of Japan in 1974. Details of the survey have been reported elsewhere (Imaizumi and Inouye, 1979; Imaizumi, Asaka, and Inouye, 1980). Among items included in Survey A, informations on maternal age, occupation of the heads of the household, sex of twins, live birth or fetal death, spontaneous or induced termination of pregnancy in case of fetal death, month of the year of live birth or fetal death were used in the present analysis.

Numbers of $\mathrm{MZ}$ and $\mathrm{DZ}$ twin deliveries were estimated by Weinberg's method. In computing the $\mathrm{MZ}$ and the $\mathrm{DZ}$ twinning rates according to month of conception and occupation of the heads of the household, total number of births taken from the annual volume of "Vital Statistics of Japan in 1974" was used as denominator.

In computing the stillbirth rates separately for $M Z$ and $D Z$ twins, the numbers of twin individuals (live birth or stillbirth) were obtained after the numbers of $\mathrm{MZ}$ and $\mathrm{DZ}$ twin pairs were estimated for each category of survival states of twins: two live-born, one live-born and one still-born, and two still-born. Then the stillbirth rate of twins was taken among $\mathrm{MZ}, \mathrm{DZ}$, and total twin deliveries, where the number of pairs with one live-born and one still-born was divided by 2 .

\section{RESULTS}

Seasonal variation in twinning rates

Table 1 and Fig. 1 show numbers and rates per 1,000 births of MZ and DZ twins according to month of conception, which was allotted to 38 weeks before expected full term delivery. The highest twinning rates for $M Z$ (4.56) and $D Z$

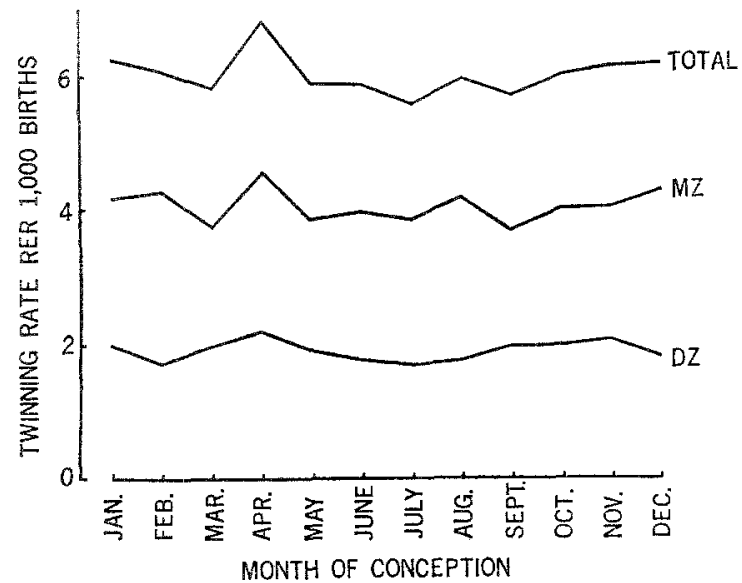

Fig. 1. Tota", MZ, and $\mathrm{DZ}$ twinning rates according to the month of conception, 1974. 
Table 1. Monozygotic and dizygotic twin deliveries and twinning rates per 1,000 births according to month of conception, 1974.

\begin{tabular}{lccccc}
\hline \multirow{2}{*}{$\begin{array}{c}\text { Month of } \\
\text { conception }\end{array}$} & \multicolumn{2}{c}{ MZ twins } & & \multicolumn{2}{c}{ DZ twins } \\
\cline { 2 - 3 } \cline { 5 - 6 } \cline { 5 - 6 } January & Number & Twinning rate & & Number & Twinning rate \\
February & 657 & 4.16 & & 316 & 2.00 \\
March & 701 & 4.26 & & 284 & 1.73 \\
April & 675 & 3.75 & & 356 & 1.98 \\
May & 740 & 4.56 & & 356 & 2.20 \\
June & 654 & 3.84 & & 332 & 1.95 \\
July & 675 & 3.97 & & 304 & 1.79 \\
August & 655 & 3.84 & & 292 & 1.71 \\
September & 688 & 4.17 & & 296 & 1.79 \\
October & 683 & 3.69 & & 368 & 1.99 \\
November & 734 & 4.02 & & 360 & 1.97 \\
December & 705 & 4.05 & 362 & 2.08 \\
Total & 736 & 4.29 & 316 & 1.84 \\
& 8,303 & 4.04 & 3,942 & 1.92 \\
\hline
\end{tabular}

(2.20) twins were seen in April, whereas the lowest rate was seen in September (3.69) for $M Z$ twins and in July (1.71) for DZ twins.

\section{Seasonal variation of stillbirth rate of twins}

Table 2 shows the numbers and rates of stillbirths of $M Z$ and $D Z$ twins according to month of birth. In MZ twins the highest stillbirth rate was seen in June $(0.1579)$ and the lowest rate in December (0.1093). In DZ twins the corresponding values were 0.1273 in May and 0.0757 in December, respectively.

\section{Variation of twinning rate among social classes}

Table 3 shows the number of twin deliveries according to the categories of survival states of twins, sex of twins, and the occupation of the heads of the household, which was classified into six classes according to the classification in the certificate records: I (Agriculture only), II (Agriculture with other works), III (Self employed), IV (Employee-white collar), V (Employee-blue collar) and VI (Others). Numbers and twinning rate of $\mathrm{MZ}$ and $\mathrm{DZ}$ twins, are computed from Table 3 (Table 4). The MZ twinning rates are similar in all classes of the occupation of the heads of the household, whereas the highest $D Z$ twinning rate was seen in class I ( 2.13 per 1,000 births) and the lowest rate in class V (1.75 per 1,000 births).

Variation of stillbirth rate of twins among social classes

Table 5 and Fig. 2 show stillbirth rates for $\mathrm{MZ}$ and $\mathrm{DZ}$ twins according to 


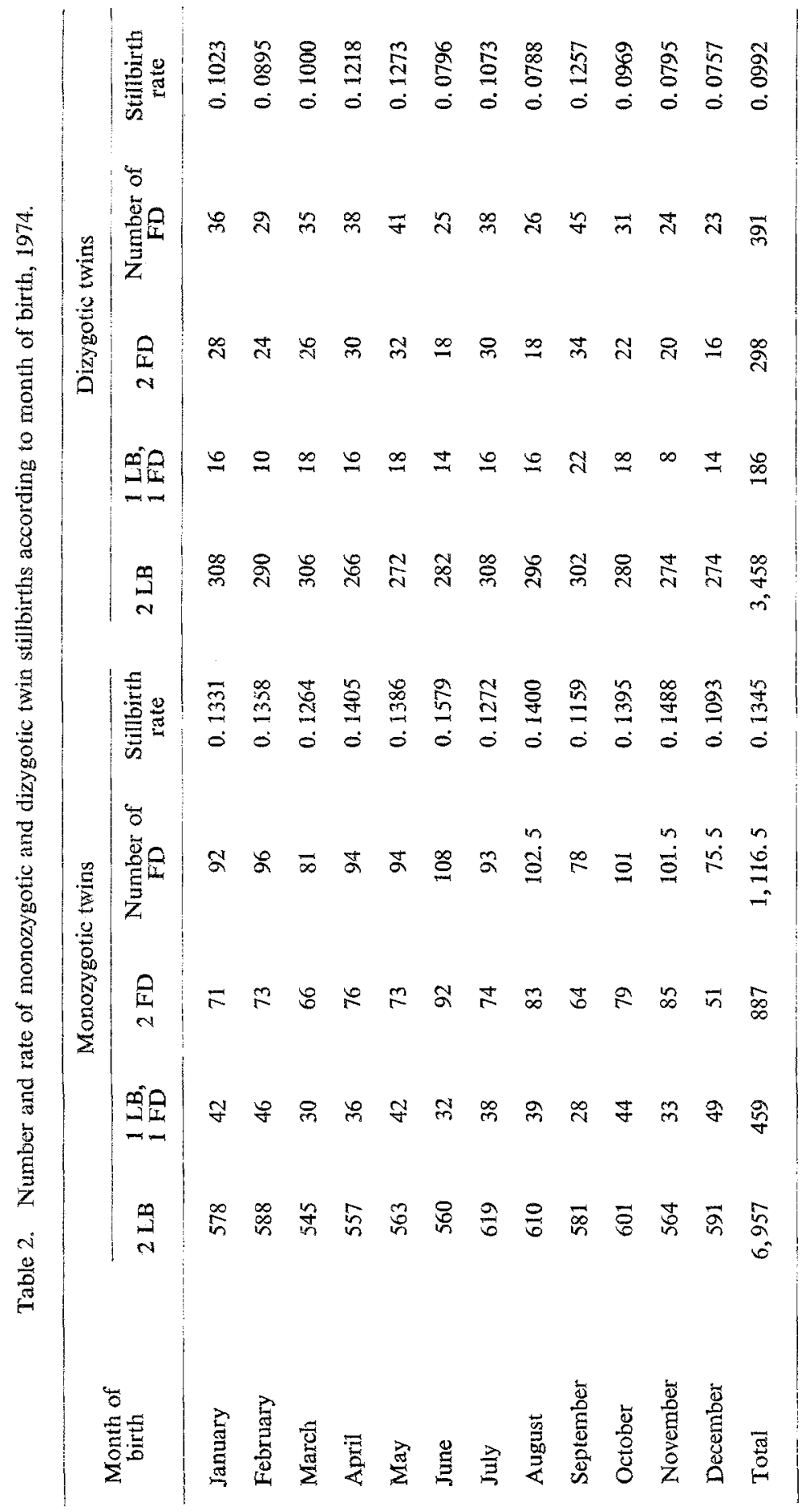

Jpn. J. Human Genet. 


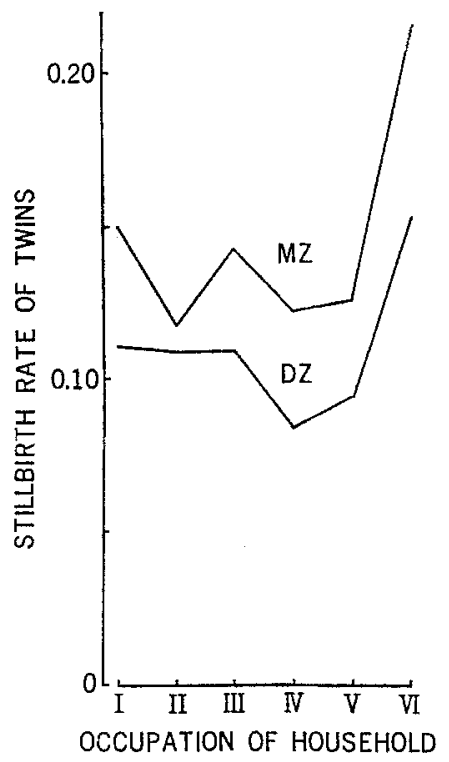

Fig. 2. Stillbirth rates of $\mathrm{MZ}$ and $\mathrm{DZ}$ twins according to the occupation of the heads of the household, 1974. For classification see text.

the occupation of the heads of the household. The highest stillbirth rate of $\mathrm{MZ}$ twins was seen in class VI $(0.2157)$ and the lowest one in class II $(0.1179)$. In DZ twins the highest stillbirth rate was similarly seen in class VI $(0.1529)$, but the lowest one in class IV (0.0842). With regard to total stillbirth rate of twins, the highest rate was seen in class VI $(0.2048)$ and the lowest one in class IV $(0.1208)$.

As also shown in Table 5, the rate of induced termination of pregnancy in twins varies from 0.0114 (class IV) to 0.0405 (class VI). In spontaneous termination of pregnancy the rate varies from 0.1047 (class II) to 0.1643 (class VI). The departure from homogeneity was significant at the $0.1 \%$ level for both rates.

\section{DISCUSSION}

Seasonal variation in twin births was studied in Scotland, England and Wales, New York, Finland, Hungary and Southern Moravia (see James, 1976). In this report he stated that there is a significant seasonality in two samples, but in five samples no significant seasonality was seen. Czeizel (1974) reported significant excess of multiple births in spring in Hungary, and James (1976) reported highly significant excess of multiple birth in the second half of the year in England and Wales. In Finland, Timonen and Carpen (1968) also reported excess twin births in spring, but he did not mention about statistical level. Kamimura (1976) studied seasonal variation in twin births in Niigata City, and concluded that high conception 


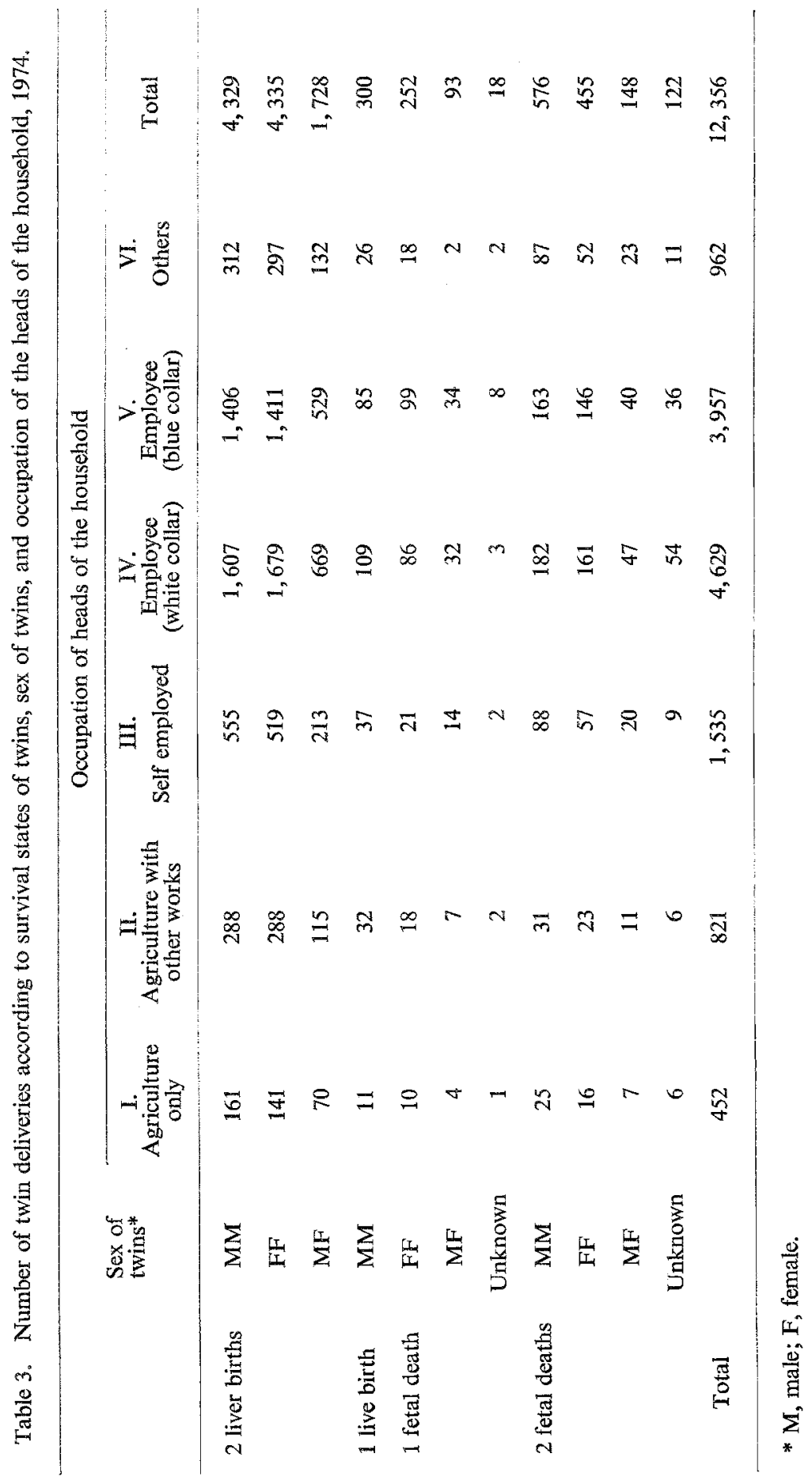




rates of twins were seen in the seasons of mild climate, spring and autumn, and low rates in hot and cold seasons. In the present study, a seasonal variation was indicated for $\mathrm{MZ}$ and $\mathrm{DZ}$ twins in overall Japan, and the highest conception rate of twins was found in April for both $\mathrm{MZ}$ and $\mathrm{DZ}$ twins. The $\mathrm{DZ}$ twinning rates are 1.86, 2.04, 1.77 and 2.01 per 1,000 births for winter (December to February), spring (March to May), summer (June to August) and autumn (September to November), respectively. It seems thus likely that twinning rates vary according to the season of conception at least in DZ twins.

In the United States, both white and Negro mothers in higher socioeconomic classes had more twin births (Myrianthopoulos, 1970). On the contrary, Lin and Chen (1968) reported a high twinning rate in lower socioeconomic classes, but their data consisted of only 129 sets of multiple births. According to MacGillivray (1970), greater decline of twinning rates in upper classes was found in Aberdeen, Scotland during the period from 1949 to 1968 . The decline associated with social class was not confirmed in Italy (James, 1975). In the present study, occupation of the heads of the household did not affect twinning rates. In the present study, stillbirth rates of twins were indicated to vary according to social class. According to Imaizumi and Inouye (1979), stillbirth rate of twins was higher in maternal age groups less than 20 years and 35 year or more for $\mathrm{MZ}$ and $\mathrm{DZ}$ twins. In the present study, mean maternal ages in occupational classes I through VI are 26.53, 26.47, $27.71,27.24,26.92$, and 27.06 years, respectively, and differences among six classes do not seem to affect stillbirth rates of twins.

Acknowledgment This investigation was supported in part by the Grand Aided by the Ministry of Health and Welfare of Japan for the Handicapped Children, 1979.

\section{REFERENCES}

Czeizel, A. 1974. Unexplainable demographic phenomena of multiple births in Hungary. Acta Genet. Med. Gemell. Suppl. 22: 214-218.

Imaizumi, Y. and Inouye, E. 1979. Analysis of multiple birth rates in Japan. I. Secular trend, maternal age effect, and geographical variation in twinning rates. Acta Genet. Med. Gemellol. 28: $107-124$.

Imaizumi, Y., Asaka, A. and Inouye, E. 1980. Analysis of multiple birth rates in Japan. II. Secular trend, and effect of birth order, maternal age and gestational age in stillbirth rate of twins. Acta Genet. Med. Gemellol. (in press)

James, W.H. 1975. The secular decline in dizygotic twinning rates in Italy. Acta Genet. Med. Gemellol. 24: 9-14.

James, W.H. 1976. Seasonality in twin births. Ann. Hum. Biol. 3: 193-195.

Japan, Ministry of Health and Welfare. 1976. Vital Statistics, 1974. Health and Welfare Statistics and Information Department, Ministry of Health and Welfare, Tokyo.

Japan, Ministry of Health and Welfare. 1977. Survey on Socio-Economic Aspects of Vital EventsPlural Births, 1975. Health and Welfare Statistics and Information Department, Ministry of Health and Welfare, Tokyo.

Jpn. J. Human Genet. 
Kamimura, K. 1976. Epidemiology of twin births from a climatic point of view. Br. J. Prev. Soc. Med. 30: 175-179.

Lilienfeld, A.M. and Pasamanick, B. 1955. A study of variations in the frequency of twin births by race and socio-economic status. Am. J. Hum. Genet. 7: 204-217.

Lin, R. and Chen, K. 1968. A preliminary twin study in Taiwan. I. Epidemiological aspect. J. Formosan Med. Ass., 67/8: 329-342.

MacGillivray, I. 1970. The changing incidence of twinning in Scotland in 1939-1968. Acta Genet. Med. Gemellol. 19: 26-29.

Myrianthopoulos, N.C. 1970. An epidemiologic survey of twins in a large, prospectively studied population. Am. J. Hum. Genet. 22: 611-629.

Timonen, S. and Carpen, E. 1968. Multiple pregnancies and photoperiodicity. Ann. Chir. Gynaec. Fenn. 57: 135-138.

Weinberg, W. 1901. Beiträge zur Physiologie und Pathologie der Mehrlingsgeburten beim Menschen. Arch. Gesamte Physiol. Menschen Tiere 88: 346-430. 